\title{
Sàng lọc và đánh giá khả năng tích lũy Polyhydroxyalkanoate từ một số chủng Bacillus sp
}

\author{
Nguyễn Thị Đà, Nguyễn Trọng Linh, Nguyễn Thu Trang, Trần Mạnh Hải, Lã Thị Huyền \\ Viện Công nghệ sinh học, Viện Hàn lâm Khoa học và Công nghệ Việt Nam
}

(Ngày đến tòa soạn: 13/8/2020; Ngày chấp nhận đăng: 28/9/2020)

\section{Tóm tắt}

Poly-hydroxyalkanoate (PHA) là polyme có khả năng phân hủy sinh học được tổng hợp bởi nhiều nhóm vi sinh vật trong điêu kiện hạn chế dinh dưỡng với vai trò làm nguồn dinh dưỡng dự trũ. Nhằm mục đích tìm kiếm và đánh giá thu chủng thuộc chi Bacillus có khả năng sản xuất của nhựa polyme phân hủy sinh học 06 chủng thuộc chi Bacillus đã được lựa chọn nghiên cứu và đánh giá. Các chủng được sàng lọc kiểm tra khả năng tích lũy poly- $\beta$-hydroxybutyrate $(\mathrm{PHB})$ bằng việc sử dụng Nile blue $\mathrm{A}$ để nhuộm và quan sát các tế bào có màu cam tích lũy poly- $\beta$ hydroxyalkanoates PHA. Kết quả cho thấy có 05/06 chủng chiếm 83,3\% có khả năng tích lũy PHA. Chủng Bacillus sp. DV01 cho thấy khả năng tích lũy cao nhất. Kết quả phân loại dựa trên trình tự $16 \mathrm{~S}$ rRNA cho thấy chủng này thuộc loài Bacillus megaterium với độ tương đông đạt $100 \%$ và được đặt tên là Bacillus megaterium DV01. Hàm lượng PHA của $B$. megaterium DV01 khi tách thu được chiếm $23,9 \%$ so với sinh khối khô.

Tư khóa: PHA, 16S rRNA, Bacillus megaterium.

\section{1. ĐĂT VẤN ĐỀ}

Việc sử dụng rộng rãi nhựa tổng hợp trong công nghiệp cũng như trong đời sống ngày nay dẫn tới nguy cơ thay đổi đa dạng sinh học bản địa và ô nhiễm môi trường bởi tính chất không phân hủy của chúng. Chính vì vậy, việc tìm kiếm và phát hiện sự có mặt của polyhydroxyalkanoate (PHA) do vi sinh vật tổng hợp ra với nhiều ưu điểm của nó như tính chất nhiệt dẻo, khả năng phân hủy cũng như tương thích sinh học và khả năng được tổng hợp từ các nguôn nguyên liệu tái tạo đã thu hút được sự quan tâm nghiên cứu rất lớn [1-2]. PHA có thể được sử dụng làm vật liệu có giá trị cho sản xuất một loạt các sản phẩm bởi các tính chất như khả năng phân hủy sinh học và khả năng tương thích sinh học cao như: bao bì thân thiện với môi trường, dược phẩm, nông nghiệp, và các ngành công nghiệp thực phẩm [3-4]. PHA không chỉ đóng vai trò trong sản phẩm sản xuất nhựa sinh học mà bởi nó không gây hại cho động vật nên nó còn được sử dụng làm phụ gia cho thức ăn của heo con và cá [5]. Ngoài chức năng dự trũ năng lượng, sự có mặt của PHA trong tế bào chất làm tăng sức đề kháng của các vi sinh vật dưới điều kiện thay đổi $p H$, nhiệt độ và áp suất thẩm thấu, và khi tiếp xúc với hóa chất độc hại [6]. Sản phẩm thuộc nhóm PHA bao gôm: poly- $\beta$-hydroxybutyrate (PHB), Polyhydroxyvalerate (PHV), polydroxyhexanote $(\mathrm{PHH})$, poylhydroxyoctanoate $(\mathrm{PHO}), \ldots$ Trong đó, $\mathrm{PHB}$ là $\mathrm{PHA}$ đơn giản nhất và được nghiên cứu cũng như ứng dụng nhiêuu nhất trong nhóm này. $\mathrm{PHB}$ được tổng hợp như nguồn dự trữ năng lượng trong rất nhiêu vi sinh vật khác nhau thuộc chi Alcaligenes, Azotobacter, Bacillus, Klebsiella, Pseudomonas, Rhizobium, Staphylococcus và Rhodococcus. Chi Bacillus là vi khuẩn 
gram dương đầu tiên được phát hiện có khả năng tổng hợp PHB [7]. Khả năng tổng hợp PHA của chi này được biết đến ở các loài như: Bacillus megaterium, Bacillus cereus, Bacillus subtilis, Bacillus licheniformis, Bacillus thuringensis,... [7-10]. Chi này được ửng dụng rộng rãi trong sản xuất các sản phẩm công nghiệp do đặc tính an toàn, khả năng tiết và độ bền của plasmid tái tổ hợp. Chi Bacillus là đối tượng nghiên cứu tiềm năng cho sản xuất PHB bởi nó có khả năng lên men trong môi trường nghèo dinh dưỡng cũng như có khả năng sử dụng rất nhiều nguồn carbon khác nhau để tổng hợp PHA [11].

Với mong muốn tìm kiếm chủng thuộc chi Bacillus có khả năng sinh tổng hợp và tích lũy PHA nhằm ứng dụng trong lên men thu PHA từ các nguôn Carbon khác nhau, trong nghiên cứu này, 06 chủng thuộc chi này được sàng lọc khả năng tổng hợp, tích lũy PHB thông qua phương pháp nhuộm huỳnh quang sử dụng Nile Blue A.

\section{VẠT LIỆU VÀ PHƯƠNG PHÁP NGHIÊN CƯUU}

\subsection{Chủng giống}

Sáu (06) chủng thuộc chi Bacillus được sử dụng trong nghiên cứu này bao gồm Bacillus sp. DV01, Bacillus sp. DV01, Bacillus subtilis KL1, Bacillus subtilis KL2, Bacillus subtilis KL3. Bacillus sp. M1. Các chủng nghiên cứu được lưu giữ trong bộ sưu tập chủng giống phòng Công nghệ tế bào động vật, Viện Công nghệ sinh học, Viện Hàn lâm Khoa học và Công nghệ Việt Nam.

\subsection{Môi trường và điều kiên nuôi cấy chủng}

\subsubsection{Môi trường}

Chủng nghiên cứu khi bảo quản lạnh được hoạt hóa bằng cách nuôi cấy $18-24 \mathrm{~h}$ ở $37^{\circ} \mathrm{C}$ trên môi trường $\mathrm{LB}$ với các thành phân $(\mathrm{g} / \mathrm{L})$ : Peptone (10), cao nấm men (5), $\mathrm{NaCl}(5)$.

Khoáng 1: Môi trường nuôi cấy chủng cho lên men pha 1 được xác định là môi trường khoáng cơ bản [8] với một số cải tiến các thành phần $(\mathrm{g} / \mathrm{L})$ : $\mathrm{Na}_{2} \mathrm{HPO}_{4} \cdot 2 \mathrm{H}_{2} \mathrm{O}(4,5) ; \mathrm{KH}_{2} \mathrm{PO}_{4}$ $(1,5) ; \mathrm{MgSO}_{4} \cdot 7 \mathrm{H}_{2} \mathrm{O}(0,2) ;\left(\mathrm{NH}_{4}\right) \mathrm{SO}_{4}(2) ; \mathrm{CaCl}_{2} \cdot 2 \mathrm{H}_{2} \mathrm{O}(0,02) ; \mathrm{NH}_{4} \mathrm{Fe}(\mathrm{III})$ Citrate $(0,05)$; cao nấm men (5); peptone (5) glucose (10). Khoáng 2: Môi trường lên men pha 2 thu $\mathrm{PHA}(\mathrm{g} / \mathrm{L})$ : $\mathrm{Na}_{2} \mathrm{HPO}_{4} \cdot 2 \mathrm{H}_{2} \mathrm{O}(4,5) ; \mathrm{KH}_{2} \mathrm{PO}_{4}(1,5) ; \mathrm{MgSO}_{4} \cdot 7 \mathrm{H}_{2} \mathrm{O}(0,2) ;\left(\mathrm{NH}_{4}\right)_{2} \mathrm{SO}_{4}(2) ; \mathrm{NH}_{4} \mathrm{Fe}$ (III) Citrate $(0,05)$; glucose $(10)$; acid citric $(1)$; vi lượng $(2 \mathrm{~mL})$. Dung dịch vi lượng $0,1 \mathrm{~mL}$ với các thành phần (mg/L): $\mathrm{ZnSO}_{4} \cdot 7 \mathrm{H}_{2} \mathrm{O}(10) ; \mathrm{MnCl}_{2} \cdot 4 \mathrm{H}_{2} \mathrm{O}(3) ; \mathrm{H}_{3} \mathrm{BO}_{3}(30) ; \mathrm{CoCl}_{2} \cdot 6 \mathrm{H}_{2} \mathrm{O}(20) ; \mathrm{CuCl}_{2} \cdot 2 \mathrm{H}_{2} \mathrm{O}$ (1); $\mathrm{NiCl}_{2} \cdot 6 \mathrm{H}_{2} \mathrm{O}(2) ; \mathrm{Na}_{2} \mathrm{MoO}_{4} \cdot 2 \mathrm{H}_{2} \mathrm{O}$ (3). Các hóa chất do công ty uy tín của Mỹ, Đức và Trung Quốc cung cấp.

\subsection{2. Điều kiện nuôi cấy thu PHA}

Chủng nghiên cứu được nuôi lắc 120 vòng/phút, $37^{\circ} \mathrm{C}$ trên môi trường khoáng dinh dưỡng khoáng 1 qua đêm, sau đó hút thu sinh khối bằng ly tâm và bổ sung vào bình $250 \mathrm{~mL}$ chứa $100 \mathrm{~mL}$ môi trường khoáng 2 và tiến hành nuôi lắc 120 vòng/phút ở $37^{\circ} \mathrm{C}$ trong $96 \mathrm{~h}$.

\subsection{Quan sát PHA tích lũy trong tế bào}

Chủng nghiên cứu được cấy trên môi trường khoáng 1 đặc sau đó được cấy chuyển sang môi trường khoáng 2 đặc có bổ sung dung dịch Nile blue $\mathrm{A}(0,5 \mu \mathrm{g} / \mathrm{mL})$. Để thực hiện phương pháp này, Nile blue $\mathrm{A}$ được pha trong dimethylsulfoxide (DMSO) với hàm lượng $0,25 \mathrm{mg} / \mathrm{mL}$ sau đó được bổ sung vào môi trường khoáng 2 . Chủng nghiên cứu được nuôi cấy trên môi trường này sau $48 \mathrm{~h}$ được lấy ra quan sát các $\mathrm{PHA}$ tích lũy trong tế bào khi soi dưới kính hiển vi 
huỳnh quang. Tế bào tích lũy PHA sẽ có cam sáng khi bắt màu với Nile blue $\mathrm{A}$.

\subsection{Phương pháp nhuộm với Nile blue trên lam kính}

Chuẩn bị lam kính sạch và nhỏ một giọt nước vô trùng sau đó lấy sinh khối chủng nghiên cứu đã nuôi cấy trên môi trường khoáng 2 sau $48 \mathrm{~h}$. Dùng que cấy hòa chủng tan đều trong giọt nước và làm khô nhanh trên ngọn lửa đèn côn. Nhỏ $20 \mu \mathrm{L}$ Nile blue $\mathrm{A}$ (pha trong DMSO với hàm lượng $0,25 \mathrm{mg} / \mathrm{mL}$ ) dàn đều và ủ lam kính ở $55^{\circ} \mathrm{C}$ trong 10 phút. Sau đó, mẫu được lấy và nhỏ acid acetic $8 \%$ và để trong khoảng 1 phút rồi rửa 02 - 03 lần dưới vòi nước chảy nhẹ. Mẫu được làm khô và soi kính hiển vi huỳnh quang ở bước sóng $460 \mathrm{~nm}$.

\subsection{Phương pháp tách chiết PHA}

PHA của chủng nghiên cứu được tinh sạch bằng phương pháp gia nhiệt kết hợp xử lý dung môi. Sinh khối tế bào sau nuôi được thu bằng ly tâm và rửa 2 lần với dung dịch đệm phosphate, $\mathrm{pH} 7,2$ sau đó được hòa lại trong $3 \mathrm{~mL}$ đệm này và tiến hành gia nhiệt bằng lò vi sóng ở mức công suất $140 \mathrm{~W}$, quay và dừng sau mỗi 30 giây trong 15 phút. Dịch chứa tế bào sau khi gia nhiệt được chuyển sang ống thủy tinh có nút xoá sau đó bổ sung thêm dung dịch ethanol : aceton theo tỷ lệ $1: 1$, búng trộn đều sinh khối và ủ trong $1-3 \mathrm{~h}$ nhằm mục đích tăng tính thấm của màng tế bào. Tế bào sau ủ được thu bằng ly tâm ở tốc độ 5.000 vòng/phút, 15 phút và bổ sung $5 \mathrm{~mL}$ chloroform, xoáy chặt nắp và tiến hành lắc $5-6 \mathrm{~h}$ để PHA được hòa tan hoàn toàn. Hỗn hợp dung dịch được ly tâm 10.000 vòng/phút trong 10 phút và thu pha chứa chloroform chuyển ra ống thủy tinh mới. Dịch chứa chloroform và PHA hòa tan sau khi thu được bổ sung methanol lạnh theo tỷ lệ $1: 8$, tương ứng. Kết tủa PHA thu được bằng ly tâm 12.000 vòng/phút trong 20 phút được làm khô trong tủ hút và bảo quản cho các nghiên cứu tiếp theo.

\subsection{Phương pháp Crotonic xác định hàm lượng nhựa sinh học}

Lượng PHA trong một mẫu được lấy có thể được xác định bằng phương pháp đo quang phổ bằng cách chuyển đổi PHA thành acid crotonic khi xử lý với acid sulfuric. Dung dịch chuẩn acid crotonic được chuẩn bị với các nồng độ tăng dần khác nhau. Độ hấp thụ của acid crotonic được đo ở bước sóng $235 \mathrm{~nm}$ từ đó xác định được phương trình chuẩn có dạng $\mathrm{y}=\mathrm{ax}$ $+\mathrm{b}$. Trong nghiên cứu này, tế bào vi sinh vật được xử lý theo phương pháp 2.4.1 đến khi thu dịch chloroform sau khi lắc hòa tan $\mathrm{PHA}$ trong tế bào bước 3 . Hút $200 \mu \mathrm{L}$ dịch chloroform chứa PHA hòa tan sau đó bổ sung $200 \mu \mathrm{H}_{2} \mathrm{SO}_{4} 98 \%$ đun $100^{\circ} \mathrm{C}$ trong 30 phút để toàn bộ PHA trong dung dịch được chuyển thành acid crotonic có màu nâu. Dung dịch sau đun được để nguội rồi tiến hành đo $\mathrm{OD}$ tại bước sóng $230 \mathrm{~nm}$. Mẫu chuẩn được sử dụng là $\mathrm{PHB}$ (Sigma) được hòa tan trong chloroform với hàm lượng $8 \mathrm{~mL} / \mathrm{mL}$, sau đó tính các nồng độ thích hợp để dựng đường chuẩn. Kết quả xác định hàm lượng PHA trong dung dịch được xác định theo phương trình xây dựng được. Mẫu đối chứng chuẩn là chloroform $+\mathrm{H}_{2} \mathrm{SO}_{4}$ và được xử lý như quy trình trên.

\subsection{Tách chiết DNA tổng số}

Chủng nghiên cứu được nuôi qua đêm trên môi trường LB sau đó ly tâm thu sinh khối và tiến hành tách chiết $\mathrm{DNA}$ tổng số theo Ausubel và cs [12]. Ly tâm thu sinh khối tế bào trong 5 phút ở tốc độ 5.000 vòng/phút. Tế bào được hòa tan đêuu trong hỗn hợp dung dịch $\mathrm{A}(567 \mu \mathrm{L}$ $\times \mathrm{TE}, 30 \mu \mathrm{l}$ SDS $10 \%$ và $3 \mu \mathrm{l}$ proteinase $\mathrm{K} 20 \mathrm{mg} / \mathrm{mL}$ ) và được ủ ở $37^{\circ} \mathrm{C}$ trong $1 \mathrm{~h}$. Sau khi ủ, bổ sung $100 \mu \mathrm{L} \mathrm{NaCl} 5 \mathrm{M}$ rồi trộn đêu. Sau bước này, $80 \mu \mathrm{L}$ dung dịch $\mathrm{CTAB} / \mathrm{NaCl}$ được bổ sung, trộn đều và mẫu được ủ trong 10 phút ở $65^{\circ} \mathrm{C}$. Bổ sung $2 \mathrm{~V}(\mathrm{v} / \mathrm{v})$ dung dịch Chloroform: isoamyl alcohol (24:1), đảo đều và ly tâm thu pha nổi phía trên sang Eppendoff mới, tiếp tục lặp lại bước 
này lần 2. DNA được thu bằng cách tủa với isopropanol $(0,6$ thể tích $(\mathrm{v} / \mathrm{v}))$ trong khoảng $1 \mathrm{~h}$ ở - $20^{\circ} \mathrm{C}$ và được rửa lại bằng $500 \mu \mathrm{L}$ ethanol (70\%). DNA được rửa, làm khô và hòa tan trong 100 $\mu \mathrm{L}$ TE. Dịch DNA được bảo quản ở $-20^{\circ} \mathrm{C}$ để dùng cho các nghiên cứu tiếp theo.

\subsection{Phương pháp phân lập gen $16 \mathrm{~S}$ rRNA}

Tách DNA tổng số các chủng và chạy PCR gene $16 \mathrm{~S}$ rRNA bằng cặp mồi: 16SF-5' AGAGTTTGATCMTGGC 3', 16SR-5' TACCTTGTTACGACT 3'. Thành phần PCR bao gồm: Dream Taq buffer $(5 \mu \mathrm{L})$, dNTP 5mM $(2 \mu \mathrm{L})$, PriF16S/ PriR16S 10pmol (1 $\mu \mathrm{L})$, DNA khuôn, Taq polymerase $(0,25 \mu \mathrm{L})$ trong $50 \mu \mathrm{L}$ phản ứng và chu kỳ chạy $\mathrm{PCR}: 95^{\circ} \mathrm{C}, 5$ phút; $\left(95^{\circ} \mathrm{C}, 1\right.$ phút; $55^{\circ} \mathrm{C}$, 1phút $20^{\prime \prime} ; 72^{\circ} \mathrm{C}, 2$ phút) $\times 30$ lần; $72^{\circ} \mathrm{C}, 7$ phút; $4^{\circ} \mathrm{C}-\infty$.

\section{KẾT QUẢ VÀ BÀN LUẬN}

\subsection{Khả năng tích lũy PHA}

Sàng lọc khả năng tích lũy PHA của các chủng nghiên cứu được đánh giá khi nuôi cấy chủng trên môi trường khoáng 2 có bổ sung Nile blue A sau 48 h. Sau khi nuôi cấy, các chủng có tích lũy PHA sẽ bắt màu cam khi soi dưới kính hiển vi huỳnh quang. Theo các tác giả đã công bố khả năng tổng hợp PHA của nhóm Bacillus rất đa dạng trong các loài như: $B$. megaterium [13], B. subtilis [7],... Trong nghiên cứu này, kết quả chụp kính hiển vi huỳnh quang cho thấy trong 06 chủng có 05 chủng có quan sát thấy hạt phát quang màu cam sáng khi soi dưới kính này (Hình 1 ). Điều này chứng tỏ có $05 / 06$ chủng có khả năng tích lũy $\mathrm{PHA}$ đó là các chủng: Bacillus sp. DV01, Bacillus subtilis KL1, Bacillus subtilis KL2, Bacillus subtilis KL3, Bacillus sp. DV02. Riêng chủng Bacillus sp M1 không có khả năng tích lũy PHA. Tại cùng điều kiện nuôi cấy, chủng Bacillus sp. DV01 cho thấy có khả năng sinh trưởng và sinh tổng hợp PHA tốt nhất trong cả 06 chủng trên môi trường khoáng. Chính vì vậy, chủng Bacillus sp. DV01 được lựa chọn để nghiên cứu phân loại, và xác định hàm lượng PHA.

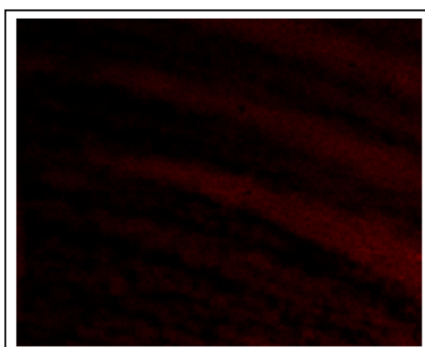

Bacillus subtilis KL1

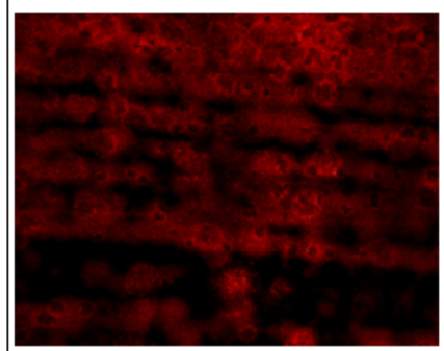

Bacillus sp. DV01

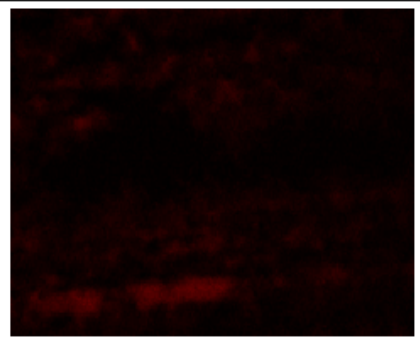

Bacillus subtilis KL2,

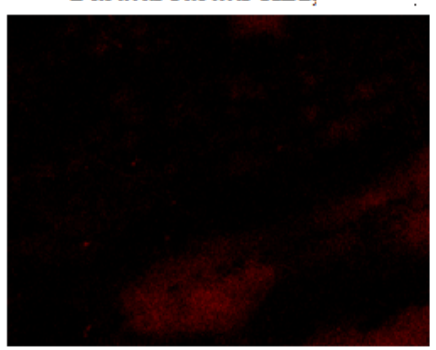

Bacillus sp. DV02

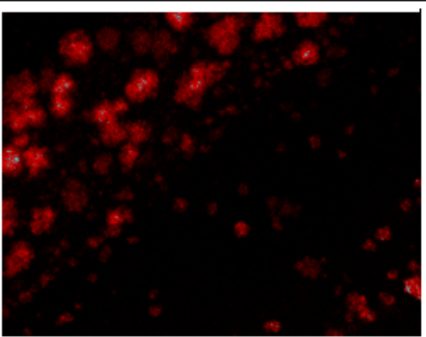

Bacillus subtilis $\mathrm{KL} 3$.

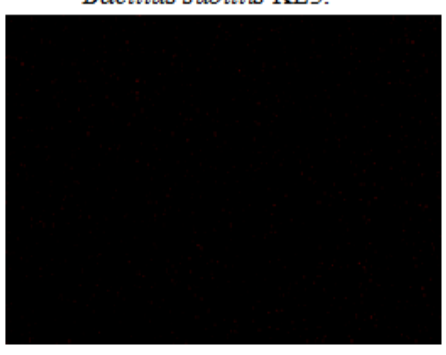

Bacillus sp. M1

Hình 1. Khả năng tích lũy PHA của chủng nghiên cứu trên môi trường khoáng có bổ sung Nile blue A quan sát duoơi kính hiên vi huỳnh quang 
Chủng Bacillus sp. DV01 nghiên cứu được nuôi cấy thu sinh khối tách thu PHA trên môi trường khoáng 2. Kết quả tách PHA từ chủng chọn lọc được thể hiện tại Bảng 1 và Hình 2.

Bảng 1. Khả năng tông hợp PHA của chủng chọn lọc

\begin{tabular}{ccc}
\hline $\boldsymbol{S T T}$ & Chi tiêu nghiên cứu & Hàm lượng $(\boldsymbol{g})$ \\
\hline 1 & Hàm lượng sinh khối khô $(\mathrm{CWD}) / 100 \mathrm{~mL}$ & 0,3615 \\
2 & Hàm lượng PHA thu được/100 mL & 0,0864 \\
3 & $\%$ PHA/CWD & $23,9 \%$ \\
\hline
\end{tabular}
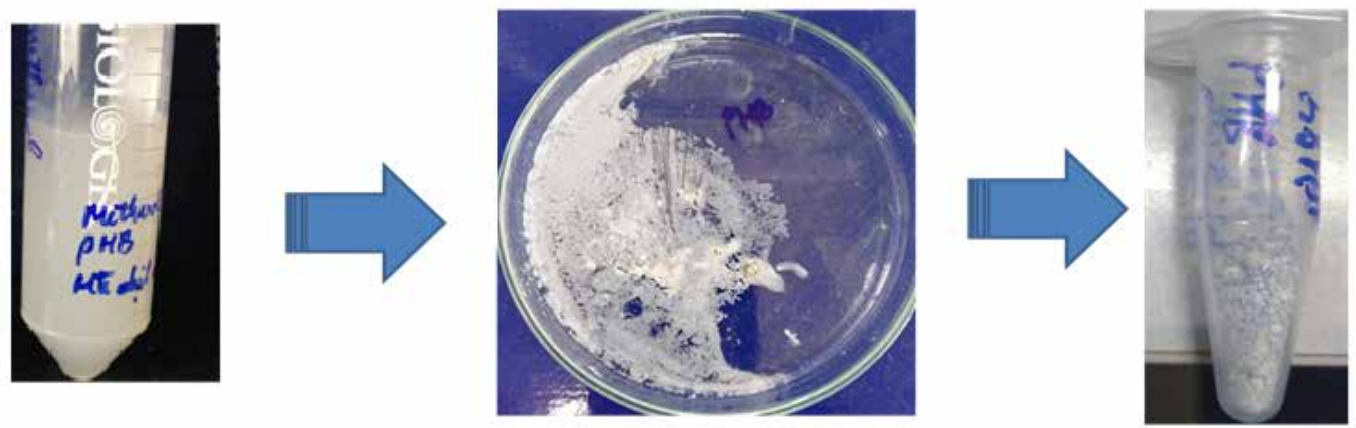

Hình 2. Hình ảnh kết quả tách PHA của chủng chọn lọc

Khi nuôi cấy trên môi trường khoáng 2, bằng phương pháp crotonic cho thấy chủng DV01 có khả năng tích lũy PHA với được $1,231 \mathrm{~g} / \mathrm{mL}$ dịch nuôi cấy tương ứng với 34,05\% PHA. Kết quả này tương ứng với công bố của Wu và cộng sự khi đánh giá khả năng tích lũy hàm lượng PHA của chủng Bacillus sp. JMa5 đạt 25 - 35\% [14]. Tuy nhiên, khi tách thu PHA từ chủng nghiên cứu DV01 bằng phương pháp gia nhiệt kết hợp hàm lượng $\mathrm{PHA}$ chỉ đạt được $0,864 \mathrm{~g} / \mathrm{L}$ tương ứng 23,9\% với lượng sinh khối khô của chủng chọn lọc thu được là 3,615 g/L.

\section{2. Đặc điểm phân loại của chủng chọn lọc}

Chủng Bacillus sp. DV01 được nuôi cấy qua đêm trên môi trường $\mathrm{LB}$ ở $37^{\circ} \mathrm{C}$ sau đó tiến hành tách chiết DNA tổng số theo phương pháp $\mathrm{CTAB} / \mathrm{NaCl}$ của Ausubel và cs, 1994 [12]. Hình thái khuẩn lạc chủng nghiên cứu được thể hiện trên hình 3A. Kết quả khuếch đại gen $16 \mathrm{~S}$ rRNA của chủng chọn lọc được thể hiện trên Hình 3B. Dựa vào kết quả điện di đồ trên hình $3 \mathrm{~B}$ cho thấy, sản phẩm PCR bắt cặp đặc hiệu với gen $16 \mathrm{~S}$ rRNA tại một băng vạch duy nhất có kích thước khoảng 1500 bp (Hình 3B). Sản phẩm PCR thu được, được tinh sạch và được giải trình tự.

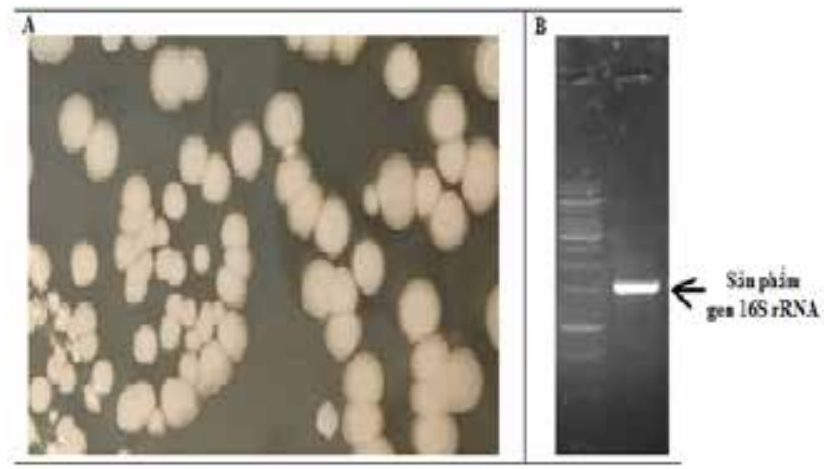

Hình 3. Hình ảnh khuẩn lạc trên môi trường $L B(A)$ và điện di đồ sản phẩm PCR gen $16 \mathrm{~S}$ rRNA (B) của chüng Bacillus sp. DV01 
Kết quả đọc trình tự Gen $16 \mathrm{~S}$ rRNA của các chủng đã được xử lý bằng phần mềm xử lý trình tự MEGA6.0, BioEdit, Chromas,...và trang web trực tuyến như http://ncbi.nlm.nih.gov thu được đoạn gen $16 \mathrm{~S}$ rRNA có độ dài 1421 nucleotide và so sánh với dũ liệu về gen này đã được cung cấp trên Genbank. Kết quả so sánh sự tương đông trình tự gen $16 \mathrm{~S}$ rRNA của chủng nghiên cứu với trình tự $16 \mathrm{~S}$ rRNA của một số chủng thuộc chi Bacillus trên ngân hàng gen NCBI được trình bày trên Bảng 2.

Bảng 2. Kết quả so sánh sự tương đông trình tự gen $16 \mathrm{~S}$ rRNA của chủng nghiên cứu với trình tự $16 S$ rRNA của một số chủng thuộc chi Bacillus trên ngân hàng gen NCBI

\begin{tabular}{ccccc}
\hline Mã chủng & Chủng so sánh & $\begin{array}{c}\text { Chiều dài gen } \\
\text { so sánh }\end{array}$ & $\begin{array}{c}\text { Điểm sai } \\
\text { khác }\end{array}$ & $\begin{array}{c}\text { Độ tương } \\
\text { đồng (\%) }\end{array}$ \\
\hline MH064437.1 & B. megaterium NA2-14 & 1421 & 0 & 100 \\
MK389288.1 & B. megaterium N15270 & 1421 & 0 & 100 \\
MT033060.1 & B. megaterium BHS1 & 1421 & 0 & 100 \\
MT184834.1 & B. megaterium NEPZ-22 & 1421 & 0 & 100 \\
NR_024697.1 & B. mycoides DSM 11821 & 1425 & 74 & 94,246 \\
NR_074540.1 & B. cereus ATCC 14579 & 1425 & 75 & 94,175 \\
NR_043403.1 & B. thuringiensis IAM 12077 & 1425 & 77 & 94,035 \\
NR_043242.1 & B. pumilus ATCC 7061 & 1422 & 83 & 93,812 \\
NR_024689.1 & B. atrophaeus JCM 9070 & 1424 & 90 & 93,118 \\
NR_112116.2 & B. subtilis IAM 12118 & 1425 & 88 & 93,123 \\
NR_075005.2 & B. velezensis FZB42 & 1425 & 89 & 93,053 \\
NR_074923.1 & B. licheniformis ATCC 14580 & 1425 & 92 & 92,842 \\
NR_025446.1 & B. halodurans DSM 497 & 1404 & 92 & 93,091 \\
\hline
\end{tabular}

Kết quả trên Bảng 2 cho thấy trình tự gen 16S rRNA của chủng Bacillus sp. DV01 có độ tương đồng $100 \%$ so với các chủng $B$. megaterium được so sánh (MH064437.1; MK389288.1; MT033060.1; MT184834.1). Dựa trên kết quả trình tự gen $16 \mathrm{~S}$ rRNA này chủng Bacillus sp. DV01 được phân loại thuộc loài Bacillus megaterium. Dựa trên trình tự gen $16 \mathrm{~S}$ rRNA đã xây dựng được cây phát sinh chủng loài của chủng tuyển chọn. Cây phát sinh chủng loại được xây dựng theo phương pháp Neighbor joining sử dụng phép toán Tamura - Nei với độ lặp lại 1.000 lần trên phần mềm chuyên dụng. Kết quả phân tích cây phát sinh loài của chủng tuyển chọn được trình bày trên Hình 4.

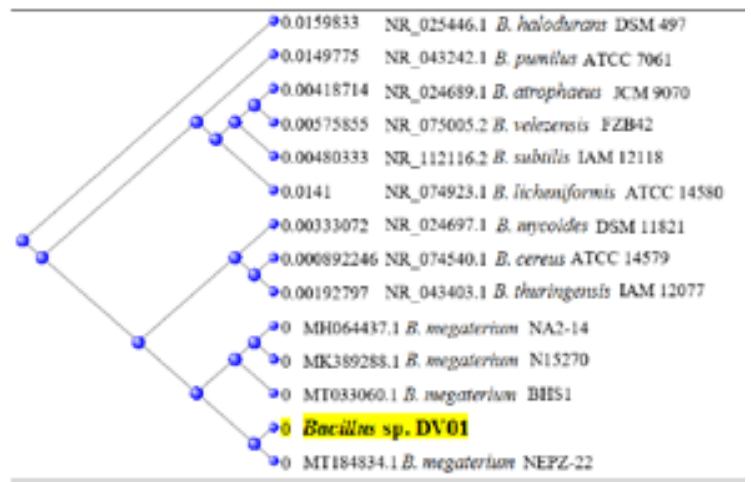

Hình 4. Cây phát sinh loài của chủng chọn lọc dựa trên phần mềm MEGA 6 


\section{KẾT LUẬN}

Từ 06 chủng thuộc chi Bacillus được lưu giữ đã xác định được 05 chủng có khả năng bắt màu Nile blue khi nuôi cấy trên môi trường khoáng cơ bản cải tiến. Thông qua nghiên cứu, chủng Bacillus sp. DV01 được lựa chọn để phân loại và xác định khả năng tích lũy PHA. Dựa trên trình tự $16 \mathrm{~S}$ rRNA cho thấy chủng này thuộc loài Bacillus megaterium và cho thấy có thể tích lũy được $0,864 \mathrm{~g} / \mathrm{L}$ PHA khi nuôi cấy trên môi trường khoáng 2 có cải tiến.

\section{LỜI CẢM ƠN}

Đây là công trình được thực hiện nhờ sự hỗ trợ kinh phí của để tài Bộ Công thương của TS Nguyễn Thị Đà với đề tài được cấp: "Nghiên cứu tạo chế phẩm sinh học tái tổ hợp sinh tổng hợp bioplastic từ phụ phẩm chế biến thủy sản” ĐT.08.19/CNSHCB.

\section{TÀI LIỆU THAM KHẢO}

[1]. K. Yasotha, M. K. Aroua, K. B. Ramachandran, and I. K. P. Tan, "Recovery of mediumchain-length polyhydroxyalkanoates (PHAs) through enzymatic digestion treatments and ultrafiltration", Biochemical Engineering Journal, vol. 30, no. 3, pp. 260-268, 2006.

[2]. M. Koller, "Switching from petro-plastics to microbial polyhydroxyalkanoates (PHA): the biotechnological escape route of choice out of the plastic predicament?", Euro Biotech Journal, vol. 3, no. 1, pp. 32-44, 2019.

[3]. D. C. Meng, R. Shen, H. Yao, J. C. Chen, Q. Wu, G. Q. Chen, "Engineering the diversity of polyesters", Current Opinion Biotechnology, vol. 29, pp. 24-33, 2014.

[4]. G. Q Chen, "In Plastics from Bacteria: Natural Functions and Applications", vol. 14, Springer Science \& Business Media, 2010.

[5]. X. Wang, X. J. Jiang, F. Wu, Y. Ma, "Microbial poly (3- hydroxybutyrate) (PHB) as a feed additive for fishes and piglets", Biotechnology Journal, Published online, 2019.

[6]. S. Obruca, P. Sedlacek, M. Koller, D. Kucera, I. Pernicova, "Involvement of polyhydroxyalkanoatesin stress resistance of microbial cells: biotechnological consequences and applications", Biotechnology Advance, vol. 36, no. 3, pp. 856-870, 2018.

[7]. M. Singh, S. K. Patel, and V. C. Kalia, "Bacillus subtilis as potential producer for polyhydroxyalkanoates", Microbial Cell Factories, vol. 8, no. 1, pp. 38, 2009.

[8]. A. Rodríguez Contreras, M. Koller, M. Miranda de Sousa Dias, M. CalafellMonfort, G. Braunegg, and M. S. Marqués Calvo, "High production of poly (3-hydroxybutyrate) from a wild Bacillus megaterium Bolivian strain", Journal of Applied Microbiology, vol. 114, no. 5, pp. 1378-1387, 2013.

[9]. S. Mohapatra et al., "Bacillus and biopolymer: Prospects and challenges", Biochemistry and Biophysics Report, vol. 12, pp. 206-213, 2017.

[10]. V. Gowda and S. Shivakumar, "Agrowaste-based Polyhydroxyalkanoate (PHA) production using hydrolytic potential of Bacillus thuringiensis IAM 12077", Brazilian Archieves of Biology and Technology, vol. 57, no. 1, pp. 55-61, 2014.

[11]. M. Thirumala, S. V. Reddy, and S. K. Mahmood, "Production and characterization of PHB 
from two novel strains of Bacillus spp. isolated from soil and activated sludge", Journal of Industrial Microbiology and Biotechnology, vol. 37, no. 3, pp. 271-278, 2010.

[12]. FM Ausubel, R Brent, RE Kingston, DD Moore, JG Seidman, JA Smith, K Struhl, Wiley CJ, RD Allison, M Bittner, S Blackshaw, "Current Protocols in Molecular Biology", John Wiley \& Sons, 2003.

[13]. S. R. Pandian, V. Deepak, K. Kalishwaralal, N. Rameshkumar, M. Jeyaraj, and S. Gurunathan, "Optimization and fed-batch production of PHB utilizing dairy waste and sea water as nutrient souces by Bacillus megaterium SRKP-3", Bioresource Technology, vol. 101, no. 2, pp. 705-711, 2010.

[14]. Wu, Q., Huang, H., Hu, G.H., Chen, J., Ho, K.P., Chen, G.Q., 2001, "Production of poly3-hydroxybutyrate by Bacillus sp. JMa5 cultivated in molasses media", Antonie van Leeuwenhoek, vol. 80, pp.111-118, 2001.

\title{
Screenning and determination of polyhydroxyalkanoate production by Bacillus sp. strains
}

\author{
Nguyen Thi Da, Nguyen Trong Linh, Nguyen Thi Thu Trang, Tran Manh Hai, La Thi Huyen \\ Institute of Biotechnology, Viet Nam Academy of Science and Technology, Hanoi
}

\section{Abstract}

Polyhydroxyalkanoates (PHAs) are biodegradable polymers produced by microbes as reserve material when they were cultured in a limitation of nutrients and excess $C$ source mediums. PHAs can be synthesized by various bacteria including gram positive and gramnegative bacteria. Among the PHA-producing gram-positive bacteria, Bacillus sp. produce and accumulate various monomer compositions of PHAs. In this study, about $83.3 \%$ of strains (05/06 strains) can accumulate PHAs production. Bacillus sp. DV01 accumulated a amount of PHA $23.9 \%$ of CWD after $96 \mathrm{~h}$ when cultured in modified basal medium containing $1 \%(\mathrm{w} / \mathrm{v})$ glucose. Bacillus sp. DV01 was identified by sequecing the gene coding for $16 \mathrm{~S}$ rRNA. BLAST results showed the obtained $16 \mathrm{~S}$ rRNA sequence of this strain revealed $100 \%$ with the Bacillus megaterium and so-called Bacillus megaterium DV01

Keywords: PHA, 16 S rRNA, Bacillus megaterium DV01. 